\title{
13 ellwether
}

P ublishing L tid

Date: April 17, 2002

To: $\quad$ Frank T. McAndrew

Department of Psychology

Knox College

Galesburg, IL 61401-4999

Re: Article entitled "A sociobiological analysis of namesaking patterns in 322 American families"

Enclosures (to be returned via fax):

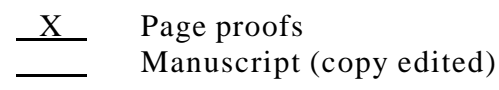

(1) The above article is to be published in:

\section{Journal of Applied Social Psychology}

(Note: The volume, issue, and page numbers will be determined after we receive your corrected proofs.)

Your manuscript has been copy edited to conform to the style and presentation of APA journals as listed in the Publication Manual of the American Psychological Association. After printing the attached file, please read the proofs carefully and mark your corrections (including typographical errors), if any, directly on the pages. Changes to abbreviation, hyphenation, or punctuation that do not conform to APA style will not be accepted.

Please proofread and return to this office at your earliest convenience, your article will not be placed into an issue until after we receive your corrected proofs. If you have any questions, please call 410-290-3870. Faxyour changes to $410-290-8726$.

(3) It is assumed that you may wish to order a quantity of reprints of your article and that such quantity will also include the requirements of your co-author(s). The price for the reprinting of your article (which includes all costs of delivering the reprints to you) is as follows:

Order submitted with page proofs

$\begin{array}{lll}100 \text { copies } & \$ & 107.80 \\ 200 \text { copies } & \$ & 151.20 \\ 300 \text { copies } & \$ & 194.60 \\ \text { Over } 300 \text { copies, } & \text { please call. }\end{array}$

Over 300 copies, please call.
Order submitted after receipt of page proofs

$$
\begin{array}{lll}
100 \text { copies } & \$ & 198.00 \\
200 \text { copies } & \$ & 224.00 \\
300 \text { copies } & \$ & 250.00 \\
\text { Over } 300 \text { copies, please call. }
\end{array}
$$

All orders for reprints must be prepaid in U.S. dollars through a U.S. bank to: Bellwether Publishing, Ltd. (FEIN 52-1814747).

\section{REMARKS:}

We would greatly appreciate your responses to the following. Please assist us by listing the names of the relevant services that you use most in your research/teachings.

Citation Index

Abstracting service

Computer database 


\title{
A Sociobiological Analysis of Namesaking Patterns in 322 American Families 1
}

\author{
FrANCIS T. MCANDREW, ${ }^{2}$ JENNIFER C. KING, AND LORA R. HONOROFF \\ Knox College
}

\begin{abstract}
A study of the naming patterns used for 648 children in 322 American families provided mixed support for a number of hypotheses that are derived from the propositions that namesaking (the naming of a child after another person) functions as advertisement of genetic kinship when it may be in doubt and as a strategy to procure future investment of resources from the father and other relatives. Males and second-born children with older sisters were more likely to be namesaked, and birth order was a significant predictor of the probability of being namesaked for males. First-borns were more likely to be named after a patrilineal relative, but there was no tendency for children born early in a marriage to be namesaked more frequently than children born after many years of marriage. Parents who themselves were namesaked were more likely to namesake their own children.
\end{abstract}

The bestowing of a name upon a child is one of the first acts of parenting that occurs in the family and it is also one of the most far-reaching. Given the longterm importance of selecting appropriate names for children, it is surprising that so little research has focused on the factors that influence this early form of parenting behavior. In this paper, we specifically will be concerned with the decision to name a child after a parent or other relative - a process we shall refer to as "namesaking." We will examine the patterns of namesaking used by parents in light of predictions derived from an evolutionary perspective in which naming can be thought of as a strategy for advertising kinship and procuring future investment of resources from the father and other relatives. We are explicitly taking the position that the naming of children in American families is more than simply a matter of following folk customs and that an application of evolutionary thinking to the study of namesaking can provide interesting insights into the patterns of namesaking used by parents.

${ }^{1}$ We would like to thank Eugene Mathes for his help in the collection of data and Elizabeth Smith for her help during the data analysis. We also would like to thank Martin Daly and three anonymous reviewers for their helpful comments on earlier drafts of the manuscript. Portions of this research were presented at the meeting of the Human Behavior and Evolution Society, Santa Barbara, California, June-July 1995, and in a keynote address delivered at the Annual Congress of the Psychological Society of South Africa, Johannesburg, September 1996.

${ }^{2}$ Correspondence concerning this article should be addressed to Frank T. McAndrew, Department of Psychology, Knox College, Galesburg, IL 61401-4999. E-mail: fmcandre@knox.edu

Journal of Applied Social Psychology, 2002, 32, ??, pp. 1-14.

Copyright $\odot 2002$ by V. H. Winston \& Son, Inc. All rights reserved. 


\section{MCANDREW ET AL.}

At its core, evolutionary theory proposes that behavioral predispositions have evolved to maximize each organism's inclusive fitness and to insure the propagation of its genes in subsequent generations (Dawkins, 1989). In many animals, parents expend considerable energy and resources in an effort to increase their offsprings' chances of surviving and reproducing. Trivers (1972) has referred to this as parental investment. Since the naming of a child does not incur obvious costs to the parents, the use of the term "parental investment" is probably inappropriate in this context. Nevertheless, choosing a name for a child may very well be an opportunity for parents to engage in a fitness-enhancing strategy very similar to those that occur during parental investment.

Considered within an evolutionary framework, namesaking a child can be an act that enhances the sense of relatedness experienced by the parents and other relatives. Namesaking a child publicly advertises the strength of the kinship between the child and its relatives, making it instantly more similar, familiar, and hence, possibly more likable to potential caregivers. For example, in a study of naming patterns in African American families between 1750 and 1925, Gutman (1977) concluded that naming is an important means of fitting the child into the kinship network and that it can be used as a way of settling old debts or positioning for future favors.

While both parents are often involved in the naming of children, the evidence is that, at least in the United States, the mother is the more influential parent when it comes to choosing a name (LeVine \& Willis, 1994). Hence, it will more often be the mother who can employ namesaking, possibly as a means of publicly identifying the father, in an attempt to increase the likelihood of a continuous provision of resources from him. Furstenberg and Talvitie (1980) were the first to suggest that namesaking might indeed be a deliberate strategy by mothers to strengthen the bond between the father and the child. They found that for children born out of wedlock, naming the child after the father proved to be a remarkably strong predictor of the quality of the long-term relationship between father and child as reflected by the amount of contact between them and the degree of financial assistance provided by the father. They also found that sons with the same first name as their fathers were reported to have fewer behavioral problems such as bedwetting, temper tantrums, and general disobedience and that they also scored higher on a standardized test of cognitive skills. Along these same lines, a recent report of an interview with a Sacramento, California, social worker confirms that more than $70 \%$ of clients of that agency who were unmarried mothers had purposively named their children after the father to encourage contact between these children and their fathers (Jankowiak \& Woodman, in press ${ }^{\mathrm{A}}$ ).

Children named after their parents like their names about as much as other children (Busse, Busse, \& Busse, 1979) and, in general, appear to acquire more advantages than disadvantages from the arrangement. However, there are situations in which boys named after fathers who explicitly carry the suffix "Jr." are 
more vulnerable to abuse or psychiatric problems, possibly because of unrealistically high expectations for the son on the part of the father (Cameron, 1987; Plank, 1971).

Evidence that namesaking is an attempt to increase perceptions of the child's genetic relatedness to the parents may be found in cases of adoption, where the need to integrate the child into its new kinship group seems to be especially pressing. The adopted newborn is more of a stranger to the parents since the biological stages of development and the rituals surrounding the impending arrival of a biological child are often lacking. Kirk (1984) reports that mothers of adopted infants do not at first share the same feelings of warmth and maternal closeness reported by biological mothers. Until recently, no studies had yet examined whether adoptive parents were more likely to engage in behaviors such as namesaking to compensate for the lack of genetic relatedness and guard against what Smith (1988) refers to as "differential parenting" and the possible tendency to dislike adopted children more than one's own natural children. It may be that the naming of nonbiological children after a parent or other relative might possibly be understood as a means of inducing others to treat the child as if it were in fact one's own genetic kin; this, in turn, would reinforce and facilitate the parents' own parenting behaviors. The biological child is recognized at birth as a family member without qualification (Kirk, 1984), but the crucial goal of integrating the child into the kin group may be especially difficult for adoptive parents. Hence, the naming of the adopted child may take on special significance in reassuring both the child and the child's new relatives that there are no important differences between the child and his or her "kin." On the other hand, the importance of the child's given name decreases when genetic kinship is assured. Johnson, McAndrew, and Harris (1991) confirmed that adopted children, in fact, were significantly more likely to be namesaked than nonadopted children and that they were more likely to be given both a first name and a middle name in honor of a relative. They also found that in biological families, but not in adoptive families, children were more likely to be named after a patrilineal relative, usually the father. They concluded that this did not happen in adoptive families because in those cases both parents were equally sure that the child was not genetically related to them.

Identifying the factors that bond parents to children is an important issue, as there is ample evidence from stepfamilies that parents invest more in biological children than in genetically unrelated children with whom they might be living, and children suffer more at the hands of adults who are not genetically related to them. In keeping with the notion of the "evil stepmother" who is a fixture in many fairy tales, research has demonstrated that the incidence of child abuse, incest, sexual abuse, and infanticide is indeed significantly higher for stepparents and other nonrelated adults than it is for biological parents, a finding that is consistent with an evolutionary perspective and also in line with data from other 
species of animals (Daly \& Wilson, 1984, 1987, 1996; Hausfater \& Hrdy, 1984; Lenington, 1981; Lightcap, Kurland, \& Burgess, 1982; Russell, 1984; Smith, 1988). It should be noted that there is no evidence that such negative effects are likely to occur in adoptive families - it is primarily a problem for stepchildren and children with a single parent who has a "live-in" partner.

The finding of a paternal namesaking bias in biological children fits nicely with the conception of namesaking as a strategy for increasing the attachment between children and their fathers. While mothers are generally confident of who their offspring are and maternal kinship is assured, many writers have pointed out that males of necessity have less confidence of paternal kinship (Barash, 1977; Daly \& Wilson, 1982; Trivers, 1972). This reality has been proposed as a possible explanation for differences between males and females, especially grandparents, in the amount of time and energy invested in children (Smith, 1988). Fathers are delighted by clear signs of paternity, since their confidence of paternity rests solely on their confidence in the mother's fidelity and on their assessment of the child's phenotypic similarity to themselves and/or known relatives (Daly \& Wilson, 1982; Daly, Wilson, \& Weghorst, 1982). Irons (1988) stresses the importance among middle-class American women that husbands recognize children as their own. Similarly, Leifer (1977) reports that pregnant women frequently fantasize that their newborns will look like their husbands. It is clearly in the mother's and child's interest to promote confidence in paternity (Kurland, 1979). The previously mentioned study by Furstenberg and Talvitie (1980) documents the benefits associated with a stronger bond between father and child, and Daly and Wilson (1981) have hypothesized that when a child is singled out for abuse in a family, it may most likely be the child who least resembles the father.

A study by Daly and Wilson (1982) illustrates how perceptions of newborns can be shaped by the anxiety of assuring paternity. In videotaped recordings of 111 American births, paternal resemblance of the neonate was spontaneously remarked on by the mother significantly more often than maternal resemblance. Paternal resemblance especially was perceived strongly in first-borns, and the bias toward seeing paternal resemblance in babies was even stronger in a separate questionnaire study of a large number of parents who had recently given birth (Daly \& Wilson, 1982). Daly and Wilson also found that when a child was named prenatally after the father, mothers were even more likely to note a paternal resemblance. The finding that paternal resemblance in infants is noted more often than maternal resemblance has been replicated in Mexican families, especially with the earliest children born when the parents have only been together for a relatively short time (Regalski \& Gaulin, 1993).

Thinking of namesaking as a strategy for advertising genetic kinship and gaining future support from fathers and other kin suggests a number of interesting hypotheses that were tested in the present study. BIf names are a limited resource that must be invested wisely, it would be predicted that males will be 
more likely than females to be namesaked. This should occur at least partially because ours is a society that traditionally has used patrilineal lineage as a means of tracing descent and allocating inheritance, and also a society in which wealth and status matter more to men's reproductive success than to women's (Low, 2000). This prediction is in keeping with previous research on nonadoptive families (Furstenberg \& Talvitie, 1980; Johnson et al., 1991; Rossi, 1965), and it is also in keeping with the ethological literature that indicates that sex-biased parental investment occurs in both humans and animals alike (Clark, Bone, \& Galef, 1990; Clark \& Galef, 1989; Hrdy, 1987; Moore \& Morelli, 1979; Smith, 1988).

If namesaking is an attempt to advertise relatedness between parents and children, it should occur most frequently in the direction of least confident genetic kinship. Thus, children who are namesaked should be more likely to be named after a patrilineal relative or parent than a matrilineal parent or relative. Because male children are more likely to be namesaked than female children, and because all children should be more likely to be namesaked patrilinealy, a third hypothesis is that male children will be more likely to be paternally namesaked than female children.

One might expect later-borns to be namesaked less often than first-borns for a variety of reasons, but if paternal namesaking is a deliberate strategy to strengthen the bond between father and child to insure the continuing provision of resources, it should become less frequent as the mother's confidence in the father's commitment increases. Therefore, paternal namesaking should become less common following a greater number of years of marriage than it would be early in marriage. Also, because a father's investment in an earlier child indicates his confidence in his wife's fidelity and a likelihood of future investment in other children, it is predicted that later-born children will be less likely to be named after the father (or any paternal relative) than first-born children.

In some cases, the factors that predispose parents toward namesaking will conflict. For example, the tendency to namesake first-borns may conflict with the desire to namesake male children if the first-born child is female. Hence, we predict an interaction between birth order and the sex of a child as follows: C C (a) First-born males will be the most likely to be namesaked paternally. (b) First-born females who are namesaked will be more likely to be namesaked paternally than later-born females. (c) Second-born children will be more likely to be namesaked if the first-born was a girl than if the first-born was a boy, but the pattern of namesaking will differ for males and females. (d) More specifically, a second-born male will be less likely to be paternally namesaked if he has an older brother than if he has an older sister. (e) A second-born female with an older sister will be more likely to be namesaked paternally than second-born females with an older brother.

To put it more generally, we predict that parents will be most likely to namesake first-born children, and also be most likely to bestow a paternal namesake 
on a first-born son. If the first-born is a female, she may be namesaked but the parents will be more likely to wait for the second child to bestow a paternal namesake, even if the second child is female. This ought to occur because many parents, especially in the United States, may see the possibility of a third child as uncertain.

\section{Method}

\section{Participants}

Participants were 322 undergraduate students (118 males, 204 females) from a small liberal arts college and a large midwestern state university. All participants were unpaid volunteers, some of whom received course credit for participation.

\section{Procedure}

Participants completed an extensive questionnaire in which they reported information about themselves and their families, such as the number of siblings, birth order of siblings, whether they were named after a relative, parent marital status at the time of birth and currently, and a variety of other questions related to namesaking and family background. The questionnaires were completed in groups of varying sizes in a large classroom. The first 112 participants in the study were not asked about the namesaking of their siblings. However, following a slight revision of the questionnaire, the next 184 participants were able to provide useable information regarding the namesaking of 327 siblings in addition to themselves, bringing the total number of individuals for whom namesaking data were available to $648^{\mathrm{D}}$ (291 males, 357 females).

\section{Results}

In the Discussion section, the data will be described in percentages and the figures will depict the results in the form of percentages. ${ }^{\mathrm{E}}$ This is being done to most efficiently and clearly convey the nature of the findings to the reader. However, all chi-square analyses are based on the raw frequencies of the participants' responses.

There were 37 individuals ( 17 males, 20 females) who were namesaked after both a paternal and a maternal relative, and there were 6 other participants ( 5 males, 1 female) who were namesaked, but the relative for whom they were named was not identified. These data were included in the descriptive percentage figures and chi-square analyses that simply examined whether or not namesaking occurred, but were omitted from any analysis or description in which the patri/ 
S Table $1^{\mathrm{S}}$

Frequency of Namesaking by Category

\begin{tabular}{|c|c|c|c|c|}
\hline & $\begin{array}{l}\text { Not named } \\
\text { after kin }\end{array}$ & Namesaked & $\begin{array}{c}\text { Number of } \\
\text { namesaked } \\
\text { children who } \\
\text { were } \\
\text { patrilineal } \\
\text { namesakes }\end{array}$ & $\begin{array}{c}\text { Number of } \\
\text { namesaked } \\
\text { children who } \\
\text { were } \\
\text { matrilineal } \\
\text { namesakes }\end{array}$ \\
\hline Male $(N=291)$ & $144(49.5 \%)$ & $147(50.3 \%)$ & $96(76.8 \%)$ & $29(23.2 \%)$ \\
\hline Female $(N=357)$ & $242(67.8 \%)$ & $115(32.2 \%)$ & $28(29.7 \%)$ & $66(70.2 \%)$ \\
\hline \multicolumn{5}{|l|}{ First-borns } \\
\hline Males $(N=116)$ & $46(39.7 \%)$ & $70(60.3 \%)$ & $46(78 \%)$ & $13(22 \%)$ \\
\hline Females $(N=141)$ & $93(66 \%)$ & $48(34.1 \%)$ & $14(37.8 \%)$ & $23(62.2 \%)$ \\
\hline \multicolumn{5}{|l|}{ Second-borns } \\
\hline Males $(N=96)$ & $48(50 \%)$ & $48(50 \%)$ & $29(70.7 \%)$ & $12(29.3 \%)$ \\
\hline Females $(N=118)$ & $75(63.6 \%)$ & $43(36.4 \%)$ & $10(26.3 \%)$ & $28(73.7 \%)$ \\
\hline \multicolumn{5}{|l|}{ Later-borns } \\
\hline Males $(N=80)$ & $50(62.5 \%)$ & $30(37.5 \%)$ & $21(84 \%)$ & $4(16 \%)$ \\
\hline Females $(N=98)$ & $74(75.5 \%)$ & $24(24.5 \%)$ & $4(21.1 \%)$ & $15(78.9 \%)$ \\
\hline
\end{tabular}

Note. Children who were namesaked after both patrilineal and matrilineal relatives and namesaked children for whom this information was not available are not included in the totals in the last two columns - the percentages reflect only clear matrilineal or patrilineal namesakes.

matrilinearity of the namesaking was an important issue. A summary of the patterns of namesaking found for the participants in this study can be found in Table 1.

As predicted $\mathrm{F}^{\mathrm{F}}$, male children were more likely to be namesaked than female children $(50.5 \%$ vs. $32.2 \%), \chi^{2}(1, N=648)=22.30, p<.0001$. In addition, namesaked male children were significantly more likely to be namesaked paternally than maternally $(76.8 \%$ vs. $23.2 \%)$, while the opposite pattern was true for females $(29.7 \%$ vs. $70.2 \%), \chi^{2}(1, N=219)=48.28, p<.0001$. Hence, namesaking showed a strong same-sex bias, with children more likely to be named after the side of the family of their same-sexed parent. This same-sex bias was not, however, a simple effect of being named after the same-sexed parent. Only $28.32 \%$ of the females who were namesaked were named after the mother, and only $34.18 \%$ of the males who were namesaked were named after the father. Hence, the namesaking that is occurring is primarily after relatives who are not the parents. 


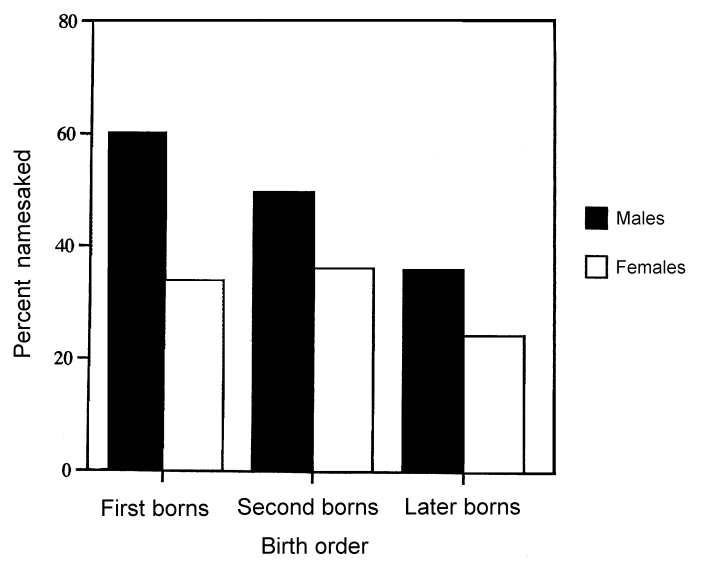

Figure 1. Frequency of namesaking by birth order and gender.

First-born males were more likely to be namesaked than second-born males, who, in turn, were more likely to be namesaked than later-born males, $\chi^{2}(2, N=$ $291)=10.52, p<.01$. There was no effect of birth order on the likelihood of females being namesaked, $\chi^{2}(2, N=357)=3.87, n s$. The relationship between birth order and namesaking for both males and females is illustrated in Figure 1.

The prediction that first-borns in general would be more likely to be paternally namesaked than later-borns was supported (45.9\% vs. $36.7 \%), \chi^{2}(1, N=$ $648)=5.32, p<.05$. Although this was true for the aggregate data, there was no significant tendency for first-born males to be paternally namesaked more frequently than second- or later-born males, $\chi^{2(2, N=125)}=1.62, n s$, and there also was no difference between first-, second-, and later-born females in the tendency to be paternally namesaked, $\chi^{2}(2, N=94)=2.06, n s$.

The interaction between birth order and sex may have been complicated by the sex of older siblings in the family. As predicted, second-born children of both sexes are more likely to be namesaked if the first-born child was female rather than male, a trend that approached significance, $\chi^{2}(1, N=177)=3.56, p<.07$. Of second-borns, $58.6 \%$ with an older sister were namesaked versus $44.4 \%$ of second-borns with an older brother. Contrary to predictions, however, secondborns were not more or less likely to receive a paternal namesake as a function of the gender of the first-born child. This was the case for both males, $\chi^{2}(1, N=$ $38)=0.08, n s$, and females, $\chi 2(1, N=29)=0.004, n s$.

A final hypothesis was that as the years of marriage increase, the mother's confidence in the father's commitment should increase and the incidence of paternal namesaking should decline. Figure 2 illustrates the relationship between years 


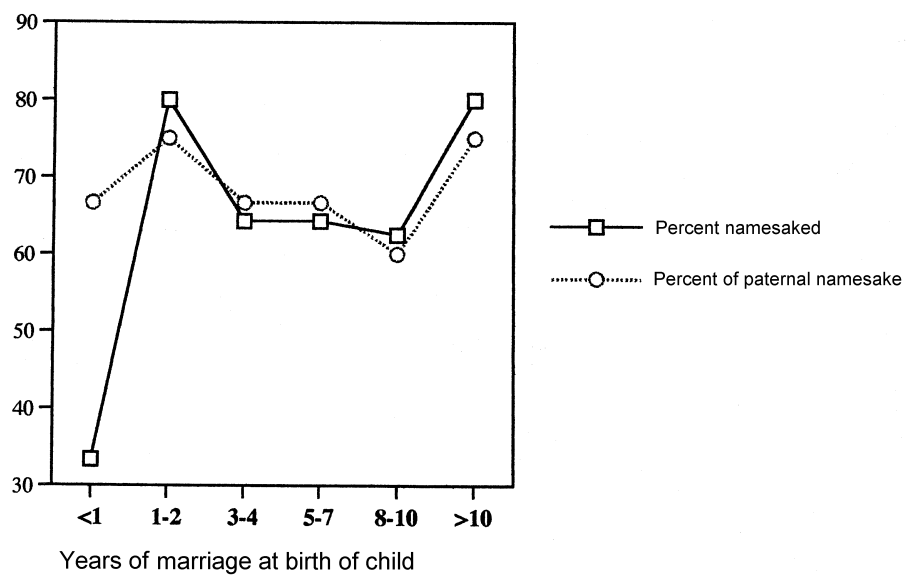

Figure 2. The relationship between namesaking and years of marriage at birth of first-born son.

of marriage at the time the child was born and the extent of namesaking for those children our data indicated would be most likely to receive a patrilineal namesake-first-born males. The figure is restricted to these children to avoid a confound ${ }^{\mathrm{G}}$ between birth order and years of marriage. The solid line represents the percentage of those children who were named after anyone, and the broken line represents the percentage of those who were named after the father or another paternal relative. (The $N \mathrm{~s}$ in several of these cells were too small to permit a meaningful statistical analysis.) The data show no clear relationship between length of marriage and either paternal namesaking or namesaking in general.

An analysis of the personal information provided by each of the 322 participants revealed several other interesting findings unrelated to the primary hypotheses. These data are from the participants only - sibling data are not included in these analyses because much of the information that is about to be discussed was requested about the participants themselves but not about their siblings.

Parents who had been namesaked themselves were significantly more likely to namesake their own children, $\chi^{2}(1, N=255)=6.31, p<.02$. This effect held true for both parents, as children with namesaked fathers were more likely to be namesaked than children whose fathers had not been namesaked $(55.6 \% \mathrm{vs}$. $39.8 \%$ ) and children with namesaked mothers also were more likely to be namesaked than children of mothers who were not namesaked (60.5\% vs. $42 \%)$. In families where both of the parents were namesaked, $73 \%$ of the children were namesaked versus $34.8 \%$ when neither parent was a namesake.

Table 2 displays the percentage of namesaked children that were namesaked with their first name, middle name, or both a first and a middle name. The data 
Table 2

Frequency of First and Middle Names as Namesakes Among Namesaked Children

\begin{tabular}{lcrr}
\hline & First name only & $\begin{array}{c}\text { Middle name } \\
\text { only }\end{array}$ & $\begin{array}{c}\text { Both first and } \\
\text { middle names }\end{array}$ \\
\hline Males $(N=69)$ & $15(21.7 \%)$ & $37(53.6 \%)$ & $17(24.6 \%)$ \\
Females $(N=89)$ & $18(20.2 \%)$ & $50(56.2 \%)$ & $21(23.6 \%)$ \\
First-borns $(N=87)$ & $18(20.7 \%)$ & $45(51.7 \%)$ & $24(27.6 \%)$ \\
Second-borns $(N=54)$ & $9(16.7 \%)$ & $33(61.1 \%)$ & $12(22.2 \%)$ \\
Later-borns $(N=17)$ & $6(35.3 \%)$ & $9(52.9 \%)$ & $2(11.8 \%)$ \\
\hline
\end{tabular}

Note. The data in this table reflect only the responses of the 322 participants-information about their siblings is not available.

consistently indicate that namesaking with a middle name was by far the most common strategy used across all categories of participants, with the probability of namesaking via a first name only or both a first name and a middle name being almost equal. Curiously, when females were namesaked, they were significantly more likely than males to be namesaked after both a paternal and maternal relative $(21 \%$ vs. $9.1 \%), \chi^{2}(1, N=147)=3.90, p<.05$.

\section{Discussion}

The results of this study offer mixed support for the evolutionary hypotheses presented in this article. Given the relatively large sample, the most reasonable explanation is that some of the hypotheses were simply off the mark. In particular, we may have overestimated the extent to which patri-namesaking is used in the United States as a strategy to bond fathers to children, at least among the socioeconomic groups from which Midwestern college students are drawn. Previous studies that have suggested that this is a common strategy (e.g., Johnson et al., 1991) have looked only at the paternal namesaking of first-borns, an effect that was replicated in this study. It may be that there is a tendency to link the father to the first-born in the family, after which time other factors become more influential in the naming of children. In hindsight, it is clear that a mother's decision to emphasize or deemphasize the connection between father and child will be a function of a great many factors, including her degree of economic security, family traditions, and the source of any wealth that may be present in the family. Hence, there may be a class bias in the tendency to use naming to strengthen the father-child bond, and this issue cannot be addressed by the data available in this study. 
The prediction that namesaking would be a more important issue for male children than for females was strongly supported in a variety of ways. Not only were males more likely to be namesaked than females, but the birth order of male children was strongly related to the probability of being namesaked, whereas for females it was virtually irrelevant. There also was clear support for the prediction that parents are more likely to delay namesaking until the second-born child if the first-born was a female. There was no support for the prediction that namesaking of first-born sons becomes less likely the longer the parents have been married.

Research in this new area is clearly in its infancy, and much needs to be done to clarify the role of naming as a strategy for managing kin relations. Avenues for future exploration must include cross-cultural studies, especially in societies with very different naming practices. The data that are available from polygamous societies and groups (e.g., Jankowiak \& Woodman, in press ${ }^{\mathrm{H}}$ ) are consistent with many of the hypotheses proposed in this article, and many rules about namesaking that exist in a variety of cultures overtly function to reassure paternity and place the child within its kinship group. For example, in Iceland and in some oriental societies, the father's name is automatically attached to the child's name in some form (e.g., Lars Johnson's son Tom becomes Tom Larson). Also, among the Kung San of Africa's Kalahari Desert, very strict rules determine how children are to be named. Every child has to be named for somebody as follows:

A first-born son is supposed to be named after his father's father, and the firstborn daughter after her father's mother. Second-born children are supposed to be named after the mother's father and mother's mother, and additional children are to be named after father's brothers and sisters and mother's brothers and sisters, in that order. More distantly related kin, and affines, may also provide names to a family. Parents may never name a child after themselves. (Lee, 1979, pp. 66-67)

In short, this study should be considered as a first step in exploring namesaking in light of evolutionary theory. As always, the value of this new perspective will be determined by the results of more extensive future investigations of this issue.

\section{References}

Barash, D. P. (1977). Sociobiology and behavior (2nd ed.). New York, NY: Elsevier.

Busse, T. V., Busse, K., \& Busse, M. (1979). Identical names for parent and child. Journal of Social Psychology, 107, 293-294.

Cameron, C. (1987). The trouble with junior: Father-naming, child abuse, and delinquency. Sociology and Social Research, 71, 200-203.

Clark, M. M., Bone, S., \& Galef, B. G., Jr. (1990). Evidence of sex-biased postnatal maternal investment by Mongolian gerbils. Animal Behaviour, 39, 735-744. 
Clark, M. M., \& Galef, B. G., Jr. (1989). Male rat pups are more hesitant to urinate in response to anogenital stimulation than are females. Developmental Psychobiology, 22, 173-182.

Daly, M., \& Wilson, M. I. (1981). Child maltreatment from a sociobiological perspective. New Directions for Child Development, 11, 93-112.

Daly, M., \& Wilson, M. I. (1982). Whom are newborn babies said to resemble? Ethology and Sociobiology, 3, 69-78.

Daly, M., \& Wilson, M. I. (1984). A sociobiological analysis of human infanticide. In G. Hausfater \& S. B. Hrdy (Eds.), Infanticide. ${ }^{\mathrm{I}}$ New York, NY: Aldine.

Daly, M., \& Wilson, M. I. (1987). Evolutionary psychology and family violence. In C. B. Crawford, M. S. Smith, \& D. Krebs (Eds.), Sociobiology and psychology: Ideas, issues, and applications. ${ }^{\mathrm{J}}$ Hillsdale, NJ: Lawrence Erlbaum.

Daly, M., \& Wilson, M. I. (1996). Violence against stepchildren. Current Directions in Psychological Science, 5, 77-81.

Daly, M., Wilson, M. I., \& Weghorst, S. J. (1982). Male sexual jealousy. Ethology and Sociobiology, 3, 11-27.

Dawkins, R. (1989) The selfish gene (2nd ed.). New York, NY: Oxford University Press.

Furstenberg, F. F., Jr., \& Talvitie, K. G. (1980). Children's names and paternal claims: Bonds between unmarried fathers and their children. Journal of Family Issues, 1, 31-57.

Gutman, H. G. (1977). The Black family in slavery and freedom: 1750-1925. New York, NY: Vintage Books.

Hausfater, G., \& Hrdy, S. B. (1984). Infanticide. New York, NY: Aldine.

Hrdy, S. B. (1987). Sex-biased parental investment among primates and other mammals: A critical evaluation of the Trivers-Willard hypothesis. In R. Gelles \& J. Lancaster (Eds.), Child abuse and neglect: Biosocial dimensions. ${ }^{\mathrm{K}}$ New York, NY: Aldine.

Irons, W. (1988). Parental behavior in humans. In L. Betzig, M. B. Mulder, \& P. Turke (Eds.), Human reproductive behavior. ${ }^{\mathrm{L}}$ Cambridge, CT: Cambridge University Press.

$\mathrm{M}$

Jankowiak, W., \& Woodman, C. (in press ${ }^{\mathrm{M}}$ ). Paternal investment or maternal investment? A critique of the parental investment hypothesis in an American polygamous community. In P. Davis \& H. Holcomb (Eds.), The evolution of minds: Psychological and philosophical perspectives.

Johnson, J. L., McAndrew, F. T., \& Harris, P. B. (1991). Sociobiology and the naming of adopted and natural children. Ethology and Sociobiology, 12, 365-375.

Kirk, H. D. (1984). Shared fate. Port Angeles ${ }^{N}$, Washington, DC: Ben-Simon.

Kurland, J. A. (1979). Paternity, mother's brother, and human sociality. In N. A. Chagnon \& W. Irons (Eds.), Evolutionary biology and human social behavior. ${ }^{\mathrm{O}}$ North Scituate, MA: Duxbury. 
LeVine, M. B., \& Willis, F. N. (1994). Public reactions to unusual names. Journal of Social Psychology, 134, 561-568.

Lee, R. B. (1979). The Dobe !Kung. P New York, NY: Holt, Rinehart, \& Winston.

Leifer, M. (1977). Psychological changes accompanying pregnancy and motherhood. Genetic Psychology Monographs, 95, 55-96.

Lenington, S. (1981). Child abuse: The limits of sociobiology. Ethology and Sociobiology, 2, 17-29.

Lightcap, J. L., Kurland, J. A., \& Burgess, R. L. (1982). Child abuse: A test of some predictions from evolutionary theory. Ethology and Sociobiology, 3, 61-67.

Low, B. S. (2000). Why sex matters: A Darwinian look at human behavior. Princeton, NJ: Princeton University Press.

Moore, C. L., \& Morelli, G. A. (1979). Mother rats interact differently with male and female offspring. Journal of Comparative and Physiological Psychology, 93, 677-684.

Plank, R. (1971). The use of "Jr" in relation to psychiatric treatment. Names, 19, 132-136.

Regalski, J. M., \& Gaulin, S. J. C. (1993). Whom are Mexican infants said to resemble? Monitoring and fostering paternal confidence in the Yucatan. Ethology and Sociobiology, 14, 97-113.

Rossi, A. (1965). Naming children in middle class families. American Sociological Review, 30, 499-513.

Russell, D. E. H. (1984). The prevalence and seriousness of incestuous abuse: Stepfathers vs. biological fathers. Child Abuse and Neglect, 8, 15-22.

Smith, M. S. (1988). Research in developmental sociobiology: Parenting and family behavior. In K. B. MacDonald (Ed.), Sociobiological perspectives on human development. Q New York, NY: Springer-Verlag.

Trivers, R. L. (1972). Parental investment and sexual selection. In B. Campbell (Ed.), Sexual selection and the descent of man ${ }^{\mathrm{R}}$ Chicago, IL: Aldine. 


\section{AUTHOR QUERIES}

A If Jankowiak \& Woodman (in press) has been published, please provide the year.

B Please reformat this section so that each hypothesis is numbered in the proper format for this journal (e.g., Hypothesis $1 . .$. ; double indented). Then, use the corresponding numbers when discussing the results of your study.

C Please reformat this section so that each hypothesis is numbered in the proper format for this journal (e.g., Hypothesis 1. ...; double indented). Then, use the corresponding numbers when discussing the results of your study.

D These numbers total $623(112+184+327=623)$. Who are the other 25 individuals?

E You should provide numbers as well as percentages in the Results and Discussion sections.

F Please use these corresponding hypotheses numbers when discussing the results of your study.

G Is "a confound" correct here?

$\mathrm{H} \quad$ If Jankowiak \& Woodman (in press) has been published, please provide the year.

I Provide the page numbers for this article.

$\mathrm{J} \quad$ Provide the page numbers for this article.

$\mathrm{K} \quad$ Provide the page numbers for this article.

L Provide the page numbers for this article.

M If this article has been published, please provide the year, page numbers, publisher, and city/state/country of publication.

$\mathrm{N} \quad$ Why is "Port Angeles" here?

$\mathrm{O} \quad$ Provide the page numbers for this article.

$\mathrm{P} \quad$ Is this title correct? If not, please make the necessary corrections.

Q Provide the page numbers for this article.

$\mathrm{R} \quad$ Provide the page numbers for this article.

$\mathrm{S} \quad$ Please be consistent with the percentages and provide one decimal place for each percentage in this table. 


\section{Annotations from 20P0066R1.pdf}

\section{Page 8}

Annotation 1; Label: Copy editor; Date: 4/17/2002 10:19:30 AM

$"(2, N=125)=1.62, n s "$ should not be superscript

Annotation 2; Label: Copy editor; Date: 4/17/2002 10:20:08 AM

"2" should be supercript after the chi

\section{Page 9}

Annotation 1; Label: Copy editor; Date: 4/17/2002 10:20:50 AM

The open parens after the superscript 2 should not be superscript

\section{Page 10}

Annotation 1; Label: Copy editor; Date: 4/17/2002 10:21:14 AM

Delete the space after chi-square 